\section{$\underset{\text { hommes }}{\text { \& migrations }}$}

\section{Hommes \& migrations}

Revue française de référence sur les dynamiques

migratoires

\section{$1290 \mid 2011$}

Travailleurs sociaux et migrations

\title{
Véronique Ahyi-Hoesle, Ayélé, fille de l'ombre
}

Éditions Bénévent, 2010, 195 pages, 16,50 euros

\section{Mustapha Harzoune}

\section{(2) OpenEdition}

\section{Journals}

\section{Édition électronique}

URL : http://journals.openedition.org/hommesmigrations/771

DOI : 10.4000/hommesmigrations.771

ISSN : 2262-3353

\section{Éditeur}

Musée national de l'histoire de l'immigration

\section{Édition imprimée}

Date de publication : 1 mars 2011

Pagination : 153

ISSN : 1142-852X

\section{Référence électronique}

Mustapha Harzoune, «Véronique Ahyi-Hoesle, Ayélé, fille de l'ombre», Hommes \& migrations [En ligne], 1290 | 2011, mis en ligne le 29 mai 2013, consulté le 22 septembre 2020. URL : http:// journals.openedition.org/hommesmigrations/771; DOI : https://doi.org/10.4000/hommesmigrations. 771

Ce document a été généré automatiquement le 22 septembre 2020.

Tous droits réservés 


\title{
Véronique Ahyi-Hoesle, Ayélé, fille de l'ombre
}

Éditions Bénévent, 2010, 195 pages, 16,50 euros

\author{
Mustapha Harzoune
}

\section{RÉFÉRENCE}

Véronique Ahyi-Hoesle, Ayélé, fille de l'ombre, Éditions Bénévent, 2010, 195 pages, 16,50 euros

1 "Je marche seule dans la vie, sans savoir où je vais. Ma vie ne m'appartient pas. Mais à qui appartient-elle? Je me sens comme une feuille qui vole au gré du vent." Qu'il est donc dur d'être métis! Du moins tant que l'on reste aimanté par l'un des deux pôles du métissage, tant que l'on n'a pas inventé une autre façon d'être au monde, libérée des chimères de l'attachement et autres illusions identitaires. Ce n'est pas Ayélé, la "fille de l'ombre", qui le démentira. Ce roman raconte l'histoire dramatiqueet tragique d'une jeune fille née des amours d'une Française et d'un Togolais. Tout va pour le mieux, mais pourtant pas question pour Marie-Eleonor de présenter Pierre Epiphane Akwune à ses parents! Pas question de franchir la ligne jaune : un "nègre" n'a rien à faire dans sa famille et Adèle, sa mère, impitoyable, veille à la pureté, sociale et raciale, des siens !

2 Aussi, quand Claudine Ayélé voit le jour, on fera ce qu'il faut pour se "débarrasser" de l'enfant aux deux prénoms. Placée en pension dans une famille ouvrière de la banlieue lyonnaise, puis chez une bobo hystérique et hostile, "la fille de l'ombre" sera, durant toute son enfance et au-delà, rejetée, salement repoussée, niée, dépréciée. Elle est la “ noiraude", la "négresse", objet de "curiosite", de "haine" et des fantasmes salaces et pervers des hommes.

3 À l'adolescence, le vent portera Claudine du côté de ses origines africaines. Alors qu'en France certains cercles militants et associatifs lui "lobotomisent le cerveau", elle s'aperçoit, dès son premier séjour chez son père, que si "la France me rejette, le Togo me garde à distance". Plus tard, elle épousera pourtant un camarade sénégalais et 
s'installera à Dakar. "La curiosité que j'ai suscitée dans la famille de Sébastien et l'hostilité à peine voilée de sa mère m'ont fait prendre conscience que je suis et resterai une étrangère." L'Afrique fit rêver la jeune Française aux origines mêlées. Elle déchante vite quand elle découvre la réalité africaine, qui, comme toute réalité humaine, ne supporte ni généralisation, ni essentialisation. Et, pour peu que la misanthropie gagne, le commerce des hommes est davantage source de déceptions que d'heureuses surprises. Enfin... Véronique Ahyi-Hoesle ne manie pas la langue de bois. Après avoir décrit l'enfance difficile de son héroïne, le rejet, abject, de sa mère, témoignant du racisme ambiant, elle ne verse pas pour autant dans une sorte d'angélisme tiers-mondiste: l'expérience africaine de Claudine-Ayélé est livrée crûment, ne cachant rien de la complexité des situations, des travers et des manigances des uns, de l'hostilité des autres et de la découverte de réelles différences culturelles. Claudine Ayélé devra souffrir pour se débarrasser de ses fausses attaches, s'émanciper et pacifier ce qui en elle s'inscrit dans deux univers culturels mais qui ne suffisent pas pour autant à la définir. Les passages sur l'enfance paraissent parfois maladroits, empruntés, sans souffle. La phrase de Véronique Ahyi-Hoesle s'anime lorsqu'il est question de l'Afrique ou de la malveillance de tel ou tel personnage. Le style peut alors devenir vachard, caustique. Quelques plages d'humour traversent aussi ce récit, notamment les face-àface entre Claudine et son grand-père maternel, vieux bougon distingué, plus nostalgique des colonies que fieffé raciste. 